\title{
PRIMEIRO CASO AUTÓCTONE DE TRIPANOSSOMÍASE AMERICANA DO ESTADO DO ACRE (BRASIL) E SUA CORRELAÇĀO COM AS CEPAS ISOLADAS DO CASO HUMANO E DE TRIATOMÍNEOS SILVESTRES DA ÁREA*
}

\author{
José Maria Soares Barata** \\ Roraima Moreira Rocha*** \\ Vera Lúcia C.C. Rodrigues**** \\ Antenor Nascimento Ferraz Filho****
}

\begin{abstract}
BARATA, J.M.S. et al. Primeiro caso autóctone de tripanossomiase americana no Estado do Acre (Brasil) e sua correlação com as cepas isoladas do caso humano e de triatomíneos silvestres da área. Rev. Saúde públ., S. Paulo, 22:401-10, 1988.
\end{abstract}

RESUMO: São apresentados os resultados obtidos na investigação entomo-epidemiológica realizada no estudo do primeiro caso humano autóctone de tripanossomíase americana no Estado do Acre (Brasil). A investigação demonstrou ausência de domiciliação triatomínea, ficando descartada totalmente a possibilidade de transmissão congênita ou transfusional. Não foi possivel verificar se a transmissão foi metaxênica através da invasão domiciliar de barbeiro silvestre, ou se por via digestiva através de alimentos contaminados. Foram isoladas duas cepas de Trypanosoma cruzi, uma do caso humano chamada Acre-Humana (AH) e outra de Rhodnius robustus coletados em palmeiras uricuri (Attalea sp) nas proximidades da casa, chamada Acre-Silvestre (AS). Ficou comprovada a existência de correlação entre os caracteres morfobiológicos e patogênicos das duas amostras estudadas: mostraram-se patogênicas para camundongos, infectando $100 \%$ dos animais, quer com formas metacíclicas de triatomíneos, quer com formas sanguicolas de doadores em fase aguda. A infeç̧ão dos camundongos nas duas amostras é grave com curto período pré-patente, parasitemia elevada e taxa de letalidade alta. Em ambas as cepas, em fase agu$\mathrm{da}$, são abundantes ninhos de amastigotas, principalmente no coração e figado. As amostras AH e AS conferem aos animais que sobrevivem boa resistencia contra infecçðes pela amostra Y. Cultivaram-se facilmente em meios líquidos e semi-sólidos e infectaram experimentalmente seis espécies de triatomíneos. Os resultados comprovam mais uma vez a presença de focos naturais desta parasitose na região.

UNITERMOS: Tripanossomose sul-americana, transmissão. Trypanosoma cruzi, isolamento. Rhodnius robustus, parasitologia. Triatomidae, parasitologia. Reservatórios de doenças.

\section{INTRODUÇÃO}

Devido à ausência de domiciliação triatomínea, a região Amazônica é considerada área indene à doença de Chagas. Entretanto, desde há muito tempo que diversos autores tem reconhecido a presença, naquela região, de focos naturais dessa doença, em razão do isolamento ou do encontro de Trypanosoma cruzi em animais e/ou triatomíneos silvestres (Castro Ferreira e Deane, 19386; Deane e Jansen, 19399; Rodrigues e Brito Melo, 1942 $2^{17}$; Deane e Damasceno, 19498; Deane, 1964'; Almeida, 19713; Almeida e Nunes de Mello, $1978^{4}$; Miles, $1983^{16}$, entre outros).

Após 1969; quando Shaw e col. ${ }^{20}$ descreveram os quatro primeiros casos autóctones hu- manos, em Belém, Estado do Pará, tem sido crescente o número de casos novos registrados em diferentes pontos daquela região. Em 1974, Lacerda Jr. e col. ${ }^{14}$ comunicam a existência do primeiro caso para o Território do Amapá, no Município de Macapá. Em 1979, Lainson e col. ${ }^{15}$ descrevem mais três casos no Pará, um em Abaetetuba e dois em Belém. Ainda em 1979 , Silveira e col. ${ }^{21}$ relatam a ocorrência de outro caso naquele Estado, na ilha do Mosqueiro. Em 1980, França e col. ${ }^{13}$ descrevem o primeiro caso no Estado do Amazonas, no Município de São Paulo de Olivença. Em 1981, Dórea ${ }^{10}$ descreve outro caso no Estado do Pará, no Município de Santo Antonio do Tauá. Em 1985, Souza Lima e col. ${ }^{22}$ descrevem outro caso no Amazonas, no Município de Barcelos. Nesse

\footnotetext{
* Apresentado na 11. Reunião Anual Sobre Pesquisa Básica em Doença de Chagas, Caxambu, 1984.

* Departamento de Epidemiologia da Faculdade de Saúde Pública da Univesidade de São Paulo - Av. Dr. Arnaldo, 715 - 01255 - São Paulo, SP - Brasil.

*** Superintendência de Campanha de Saúde Pública (SUCAM) - Rua Cel. João Donato, 125 - 69900 - Rio Branco, AC - Brasil.

**** Superintendência de Controle de Endemias (SUCEN) - Rua Afonso Pessine, 86 - 13840 - Mogi-Guaçú, SP — Brasil.
} 
mesmo ano, Rodrigues e col. ${ }^{18}$ descrevem mais um caso no Pará, no Município de São Felix do Xingú. E finalmente, em 1986, Rodrigues e col. ${ }^{19}$ descrevem mais oito casos no Amapá, todos no Município de Macapá. Perfazendo, portanto, um total de 22 casos autóctones reconhecidos e distribuídos: 10 no Pará, 9 no Amapá, 2 no Amazonas e 1 no Acre.

Embora em muitos dos referidos casos não se tenham esgotado as investigaçōes epidemiológicas, em nenhum deles evidenciou-se domiciliação triatomínea local. Para a maioria dos casos não ficou claro o mecanismo de transmissão e pelas evidências concluiu-se que a infecção ou foi através de ingestão de alimentos contaminados; ou detectou-se nas proximidades das moradias, palmeiras ou outros ecótopos naturais abrigando biocenoses dessa infecção; ou ainda, em raros casos, associou-se à invasão das casas por barbeiros silvestres.

No presente trabalho são apresentados os resultados obtidos na investigação entomo-epidemiológica do primeiro caso humano autóctone do Estado do Acre e sua correlação entre as cepas de Trypanosoma cruzi isoladas do caso humano e de triatomíneos silvestres capturados na área.

\section{MATERIAL E MÉTODOS}

Para obtenção dos dados de caracterização do caso e da região foram seguidas as normas da Superintendência de Campanha de Saúde Pública (SUCAM) para investigação de casos parasitologicamente positivos para $T$. cruzi e investigação entomológica na área, acrescidas de observações anteriromente descritas (Forattini, $1980^{11}$ e $1981^{12}$ ).

Para caracterização das cepas estudadas partiu-se de amostras de $T$. cruzi isoladas, respectivamente, por xenodiagnóstico do caso humano agudo, denominado de Acre-Humano (AH), e de uma ninfa de quinto estádio de Rhodnius robustus capturada em palmeira Attalea sp, denominada Acre-Silvestre (AS). Após isolamento, as amostras foram mantidas em camundongos brancos com 21 dias de idade, mediante inoculações intraperitoneal de sangue de doadores com infecção aguda. Os repiques feitos com 15 dias de intervalo e o inóculo foi de aproximadamente $3,5 \times 10^{6}$ tripomastigotas. Para melhor eficácia das provas de proteção as inoculaçōes foram feitas com doses menores de tripomastigotas por $\mathrm{ml}$.

Como elemento de estudo da patogenicidade, biologia e morfologia das amostras, usamos os métodos empregados e descritos por Albuquer- que e Barreto ${ }^{1,2}$ (1968). As observações foram tabeladas e confrontadas, visando à possibilidade de correlaçōes morfo-biométrica e bioló. gica entre as duas amostras.

\section{RESULTADOS OBTIDOS}

\section{Caracterização do Caso}

MAS, um ano e sete meses de idade, sexo feminino, nasceu na localidade Boa Vista (Fig. 2), atualmente incorporada ao Projeto Pedro Peixoto (Gleba U), Município de Plácido de Castro, Estado do Acre. Filha de pais seringueiros e com seis irmãos mais velhos, morou nessa localidade até a idade de um ano e um mês. Quando, então, mudou para o Projeto Redenção II (Fig. 3), distante da moradia anterior cerca de $20 \mathrm{~km}$, e pertencente ao mesmo municipio (Fig. 1). Tal caso foi detectado por busca passiva de rotina dentro do programa de controle da malária feita pela SUCAM, na área, através do Posto de Notificação n. 1397, no Município de Plácido de Castro. Classificado como febril atual foi feita gota espessa por punção digital no dia 12/7/1982 e concomitantemente medicação antimalárica supressiva de rotina (cloroquina). Como o exame hemoscópico revelou a presença de formas tripomastigotas, foi realizada nova colheita em 19 do mesmo mês, para confirmação de diagnóstico. Nessa ocasião procedeu-se também à investigação epidemiológica do caso, tendo a criança apresentado, no momento, quadro febril, e ao exame hemoscópico foj obtido o mesmo resultado anterior. Mediante informações colhidas de familiares sua história pregressa não assinalou nenhum quadro digno de nota. O exame físico revelou febre intermitente e além de quadro de anemia e anasarca compatíveis com a região, nenhuma alteração que merecesse destaque especial. Não foi possível evidenciar a porta de entrada da infecção, tendo sido negados antecedentes operatórios ou de transfusão sanguínea. Os pais declaram terem nascido no município e nunca terem viajado para fora do Estado. A mãe informou ainda nunca ter sido hospitalizada e todos seus partos terem sido realizados no próprio domicílio. Nã̃o tinham nenhum conhecimento sobre doença de Chagas e desconheciam totalmente a existência de barbeiros. No mês seguinte procedeu-se à colheita de sangue em todos os membros da família para diagnóstico de infecção chagásica, em papel de filtro para reação de imunofluorescência indireta. Paralelamente realizou-se xenodiagnóstico nos membros da familia e nos animais domésticos, com cinco 
ninfas de Triatoma infestans, 5 ninfas de Panstrongylus megistus e 5 ninfas de Rhodnius neglectus, as quais foram examinadas com 15, 30 e 45 dias. Concomitantemente iniciou-se a busca de indícios de domiciliação na casa e anexos. Naquele momento, esses exames foram todos negativos, com exceção do xenodiagnóstico da menor MAS, do qual foi isolada uma das cepas e que passou a ser chamada Acre-Humano (AH). No mês de outubro, com a confirmação dos resultados, voltou-se à área para ser feita a medicação do caso, constatando-se que a família havia mudado e tomado destino ignorado. Mensalmente até janeiro do ano seguinte foram feitas várias incursões à área para a pesquisa de triatomíneos, mesmo assim não foi possível detectar-se a direção que tomou aquela família. Os resultados dessas observações estão relacionadas no capítulo seguinte.

\section{Caracterização da Região e da Pesquisa Silvestre de Triatomíneos}

A localidade Boa Vista e o Projeto Redenção II, localidades onde, respectivamente, nasceu $e$ morou a menor MAS, pertenciam a uma área maior chamada Colônia Plácido de Castro, em município do mesmo nome, Estado do Acre.
Essa Colônia está situada a menos de $20 \mathrm{~km}$ da sede do município e está ligada à cidade de Rio Branco, capital do Estado, pela Rodovia AC-40, pela qual dista cerca de $90 \mathrm{~km}$ daquela cidade (Fig. 1). A partir de 1972, a reforma agrária dirigida pelo INCRA (Instituto Nacional de Colonização e Reforma Agrária) descaracterizou os antigos seringais. Essa Colônia, assim como vários seringais passaram a fazer parte de um projeto de colonização que tomou o nome de Projeto Pedro Peixoto. Essa reforma não só mudou a estrutura fundiária, mas, e principalmente, alterou profundamente a distribuição espacial da população local. Entretanto não conseguiu alterar as condições de higiene, habitação e alimentação daquela população. As casas onde nasceu e morou a menor MAS (Figs. 2 e 3) são típicas na região. Essas habitações continuam mantendo padrão semelhante, mesmo após a implantação da reforma. São barracas cobertas de palha (folhas de palmeira uricuri) com dois ou três cômodos, comumente com meias paredes, ou sem paredes, elevadas do solo, e freqüentemente com paredes e assoalho feitos de paxiuba (caule de palmeira Irirartea exorrhiza Mart., cortado longitudinalmente). São quase sempre construídas muito próximo da mata (capoeira), em pequenas clareiras, onde às vezes são plantados al-

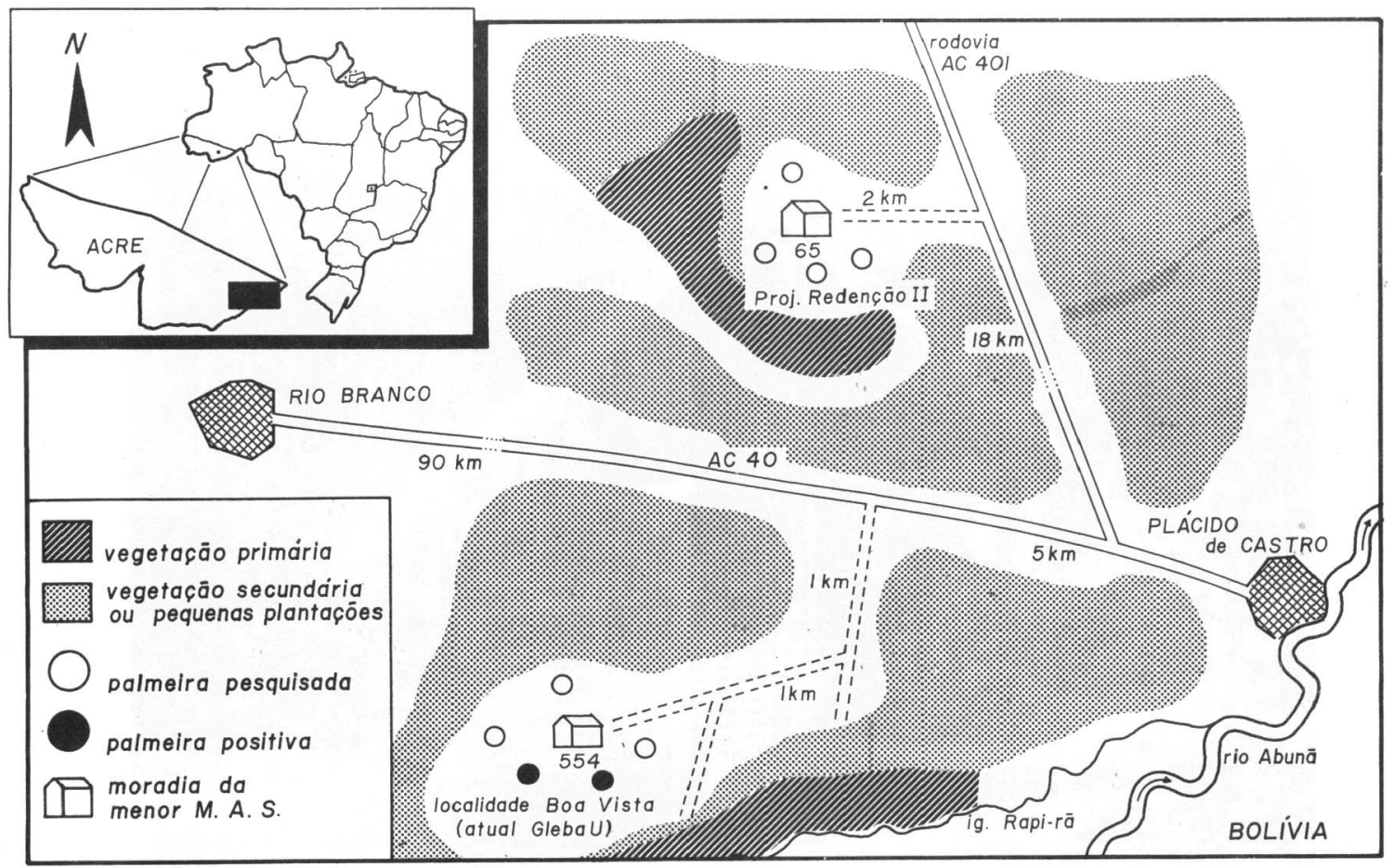

Fig. 1 - Representação esquemática do Projeto Pedro Peixoto (ex-colônia Plácido de Castro), Municipio de Plácido de Castro, área de origem das cepas de Trypanosoma cruzi isoladas do primeiro caso autóctone no Estado do Acre, Brasil. 


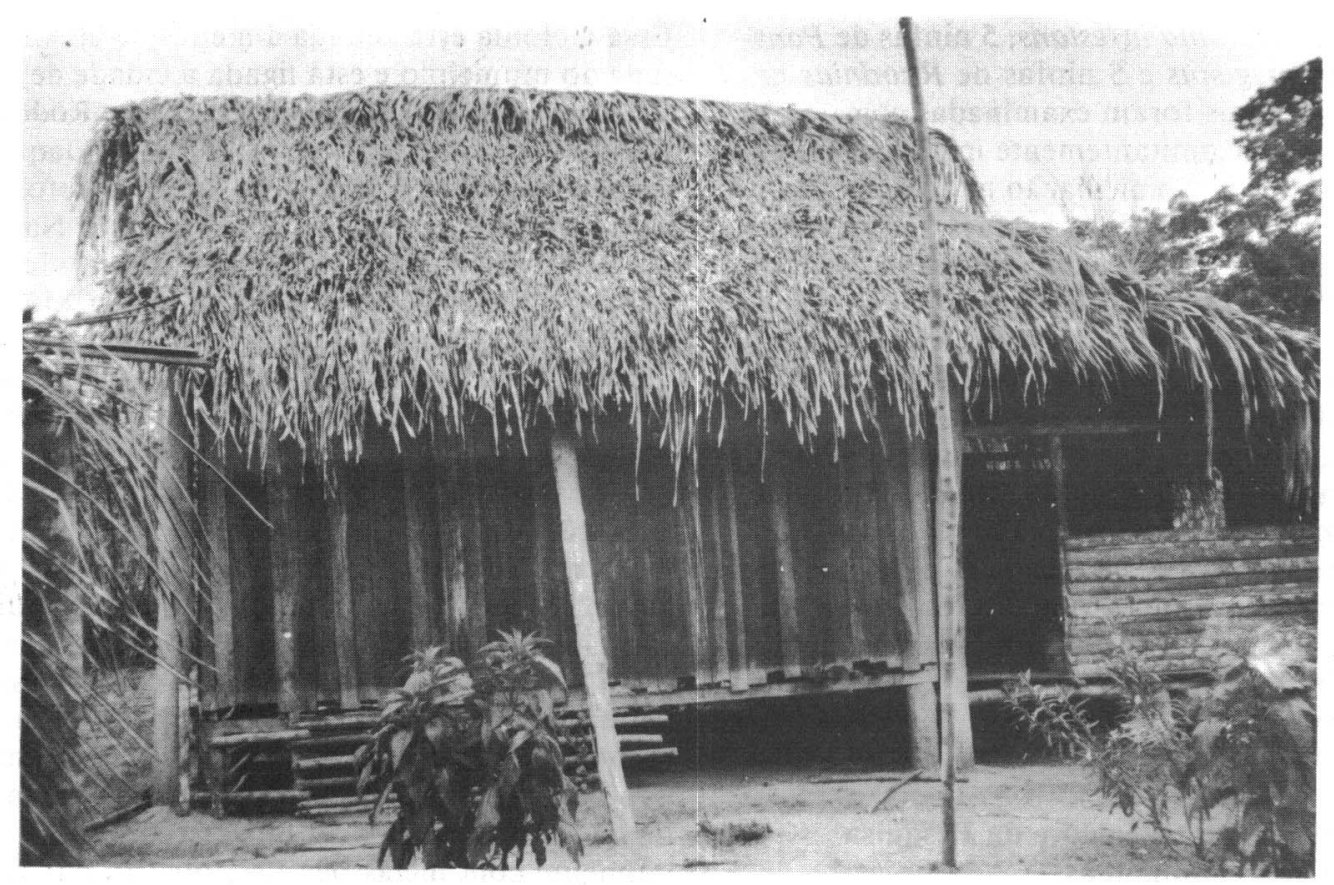

Fig. 2 - Casa onde nasceu a menor MAS, localıdade Boa lisla no Municipio de Placido de Castro, Estado do Acre.

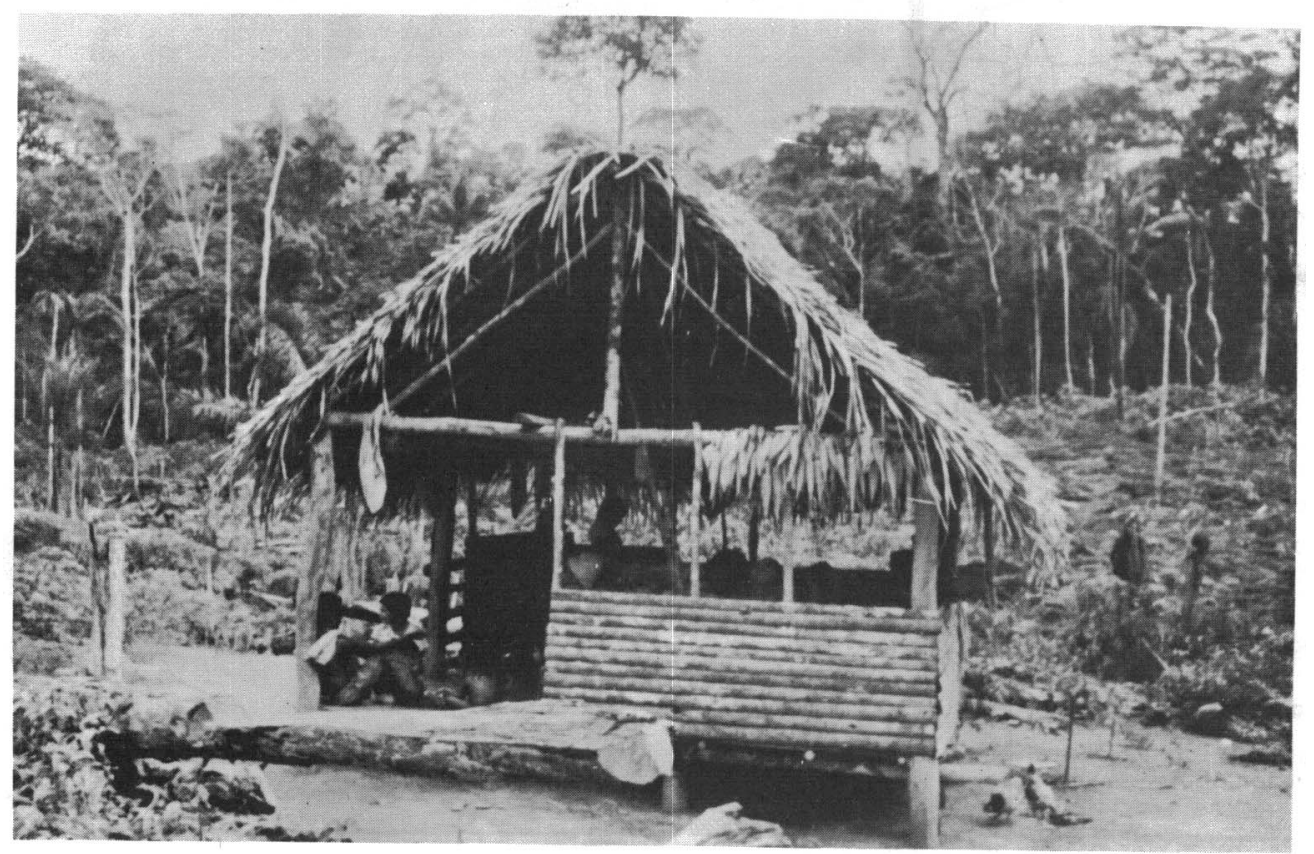

Fig. 3 - Casa onde morava a menor MAS por ocasião da notificação do caso, Projeto Redenção II, Municipıo de Plácido de Castro, Estado do Acre. 
guns pés de mandioca e milho para subsistência da família. Há em toda a área abundância de palmeiras uricuri (Attalea sp.), as quais entre outras serventias têm suas folhas utilizadas para cobertura de casas. Na pesquisa de ecótopos naturais realizados na área, entre setembro de 1982 e janeiro de 1983, foi constatada a presença de $R$. robustus em ninhos de roedores em duas dessas palmeiras que se encontravam, respectivamente, a cerca de 10 e $20 \mathrm{~m}$., da primitiva casa (Fig. 1). Nessa ocasião foi capturado um total de 29 exemplares de $R$. robustus, sendo 4 machos, 2 fêmeas e 23 ninfas. Desses, um macho, duas fêmeas e duas ninfas encontravam-se infectados com formas tripomastigotas e dos quais foi isolada a outra cepa de $T$. cruzi, a qual chamamos de Acre-Silvestre (AS). Outros tipos de ecótopos naturais foram pesquisados, todos eles, entretanto, salvo as citadas palmeiras, foram negativos.

\section{Caracterização e Correlação das Cepas}

As duas amostras (humana e silvestre) do $T$. cruzi, oriundas do Estado do Acre, determinaram no animal experimental (camundongos) uma rápida e progressiva infecção, a qual evoluiu num período de 15 dias a contar da data da inoculação, com mortalidade total dos animais dentro deste período.

Infecção em animais de laboratório - $\mathrm{Na}$ Tabela 1 encontram-se os resultados obtidos dos repiques de tripomastigotas sanguíneas em diferentes lotes de camundongos.

As duas amostras estudadas apresentaram período pré-patentes curtos, entre o segundo e terceiro dias após a inoculação. Mostraram níveis parasitêmicos em geral elevados, variando muito pouco de uma passagem para outra, atingindo niveis mais altos entre o $12^{\circ}$ e $15^{\circ}$ dias após a inoculação. Os níveis parasitários altos, aliados a precocidade de parasitemia máxima e a elevada taxa de letalidade indicam que as duas amostras em estudos são muito virulentas para camundongos.

Morfologia e biometria dos tripanossomas sanguicolas - Os tripanossomas observados em esfregaços de sangue de camundongos das duas amostras apresentaram-se pouco variáveis e têm os caracteres marcantes do $T$. cruzi: comprimento moderado, cinetoplasto volumoso e de localização terminal e subterminal, núcleo ocupando o terço médio do corpo, membrana ondulante com poucas ondulações e flagelo relativamente curto (Fig. 4).

Os resultados do estudo biométrico, baseado na micrometria de trinta tripanossomas de cada amostra, encontram-se sumariados na Tabela 2 , e mostram uma pequena diferença do comprimento total médio entre as duas amostras. A cepa AS apresenta os tripomastigotas sanguícolas um pouco maiores que a cepa $\mathrm{AH}$.

Parasitismo tissular - O exame de cortes de tecidos de camundongos mortos durante a fase aguda da infecção teve nas duas amostras presença intensa de ninhos de amastigotas na musculatura cardíaca (Fig. 5). O fígado também apresentou bom grau de parasitismo, o mesmo não ocorrendo com o esôfago, baço e intestino, órgãos esses com discreto parasitismo tissular.

Infectividade para triatomíneos - Foram empregadas seis espécies de triatomíneos procurando-se verificar a susceptibilidade das mesmas frente às duas amostras do $T$. cruzi. Foi utilizado para cada amostra ninfas do quarto estádio de $T$. infestans, Triatoma sordida, $T$. brasiliensis, $P$. megistus, $R$. neglectus e Rhodnius prolixus, distribuídas em lotes de trinta ninfas para cada espécie e amostra de $T$. cruzi (360 nf.). Os resultados obtidos por dissecção do conteúdo intestinal, 30 dias após a alimentação, encontram-se na Tabela 3 e indicam que, das espécies testadas, as que mostraram maior suscetibilidade às duas amostras em estudo foram $T$. sordida e $R$. neglectus.

TABELA 1

Caracteres gerais da infecção de camundongos pelas amostras de Tripanosoma cruzi isoladas do caso Humano e de Rhodnius robustus.

\begin{tabular}{|c|c|c|c|c|c|c|c|c|}
\hline \multirow{2}{*}{$\begin{array}{l}\text { Caracteres da } \\
\text { infecção } \\
\text { Amostra }\end{array}$} & \multirow[t]{2}{*}{$\begin{array}{c}\% \text { de } \\
\text { infecção }\end{array}$} & \multicolumn{3}{|c|}{$\begin{array}{l}\text { Periodo prepatente } \\
\text { (dias) }\end{array}$} & \multicolumn{2}{|c|}{$\begin{array}{l}\text { Limite de variação } \\
\text { da parasitemia } \\
\text { (Máxima) }\end{array}$} & \multirow{2}{*}{$\frac{\begin{array}{c}\text { Duração da } \\
\text { fase aguda }\end{array}}{\text { (dias) }}$} & \multirow{2}{*}{$\begin{array}{r}\begin{array}{r}\text { Taxa de } \\
\text { letalidade }\end{array} \\
\%\end{array}$} \\
\hline & & Mínimo & Máximo & Médio & $\mathrm{N} \varphi / \mathrm{mm}^{3}$ & dia & & \\
\hline Acre Humana & 100,00 & 2 & 3 & 2,5 & $31.730-104.500$ & $139-14 \%$ & - & 100,00 \\
\hline Acre Silvestre & 100,00 & 2 & 3 & 2,5 & $29.830-92.150$ & $139-159$ & - & 100,00 \\
\hline
\end{tabular}




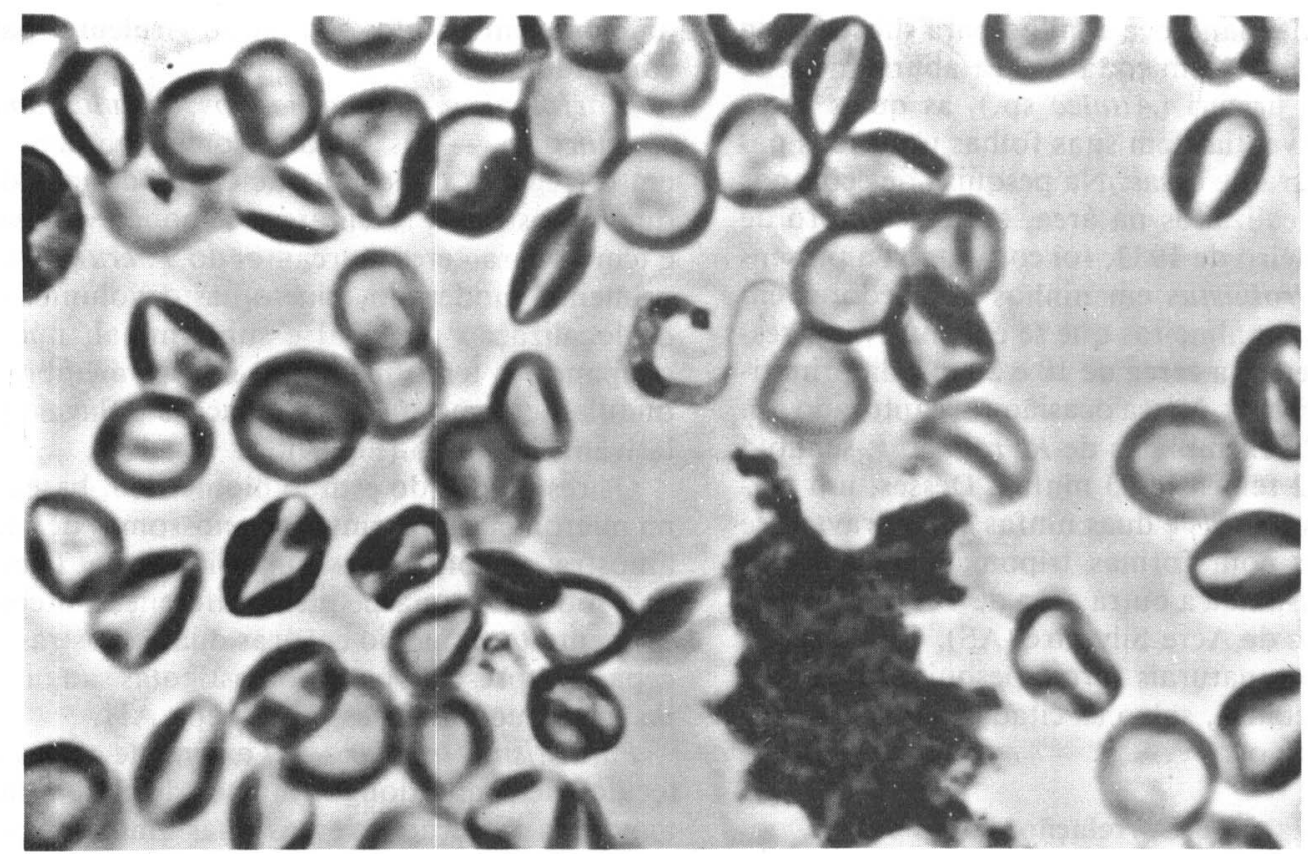

Fig. 4 - Formas tripomastigotas da amostra de $T$. cruzl cepa AH no sangue circulante de camundongo ( $1.458 \times)$.

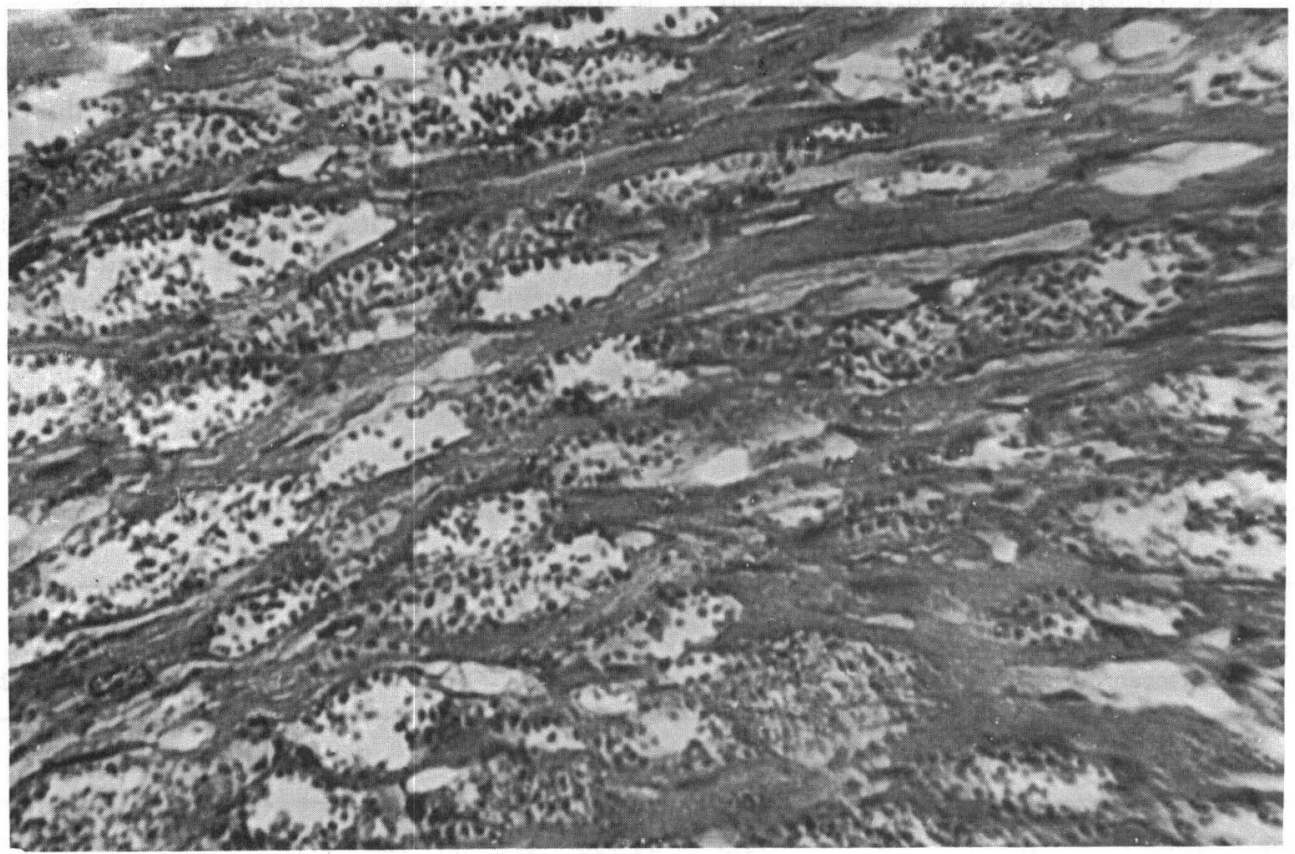

Fig. 5 - Ninhos de amastigotas da amostra de $T$. cruz cepa AH na musculatura cardiaca de camundongo ( $\$+2$ s). 
TABELA 2

Resultados da micrometria realizada em tripomastigotas sanguícolas de camundongos experimentalmente infectados, com as amostras de Tripanosoma cruzi isoladas do caso humano e de Rhodnius robustus.

\begin{tabular}{|c|c|c|c|c|c|c|}
\hline \multirow{3}{*}{ Especificaçāo } & \multicolumn{6}{|c|}{ Medidas em Micrômetros (u) } \\
\hline & \multicolumn{2}{|c|}{ Mínima } & \multicolumn{2}{|c|}{ Máxima } & \multicolumn{2}{|c|}{ Média } \\
\hline & $\begin{array}{c}\text { Acre } \\
\text { Humana }\end{array}$ & $\begin{array}{c}\text { Acre } \\
\text { Silvestre }\end{array}$ & $\begin{array}{c}\text { Acre } \\
\text { Humana }\end{array}$ & $\begin{array}{c}\text { Acre } \\
\text { Silvestre }\end{array}$ & $\begin{array}{c}\text { Acre } \\
\text { Humana }\end{array}$ & $\begin{array}{c}\text { Acre } \\
\text { Silvestre }\end{array}$ \\
\hline $\begin{array}{l}\text { Comprimento } \\
\text { do flagelo }\end{array}$ & 3,00 & 3,10 & 11,00 & 13,00 & 8,19 & 9,60 \\
\hline Distância NA & 4,90 & 5,00 & 10,00 & 12,80 & 7,55 & 8,09 \\
\hline Distância NP & 7,00 & 7,00 & 11,50 & 12,70 & 9,69 & 10,17 \\
\hline $\begin{array}{l}\text { Comprimento } \\
\text { do corpo }\end{array}$ & 14,00 & 13,50 & 18,60 & 23,80 & 17,24 & 18,20 \\
\hline $\begin{array}{l}\text { Comprimento } \\
\text { total }\end{array}$ & 22,60 & 20,00 & 31,00 & 33,00 & 25,48 & 27,90 \\
\hline $\begin{array}{l}\text { Largura do } \\
\text { corpo }\end{array}$ & 1,00 & 1,10 & 3,00 & 3,90 & 2,18 & 2,42 \\
\hline $\begin{array}{l}\text { Diâmetro do } \\
\text { cinetoplasto }\end{array}$ & 0,60 & 0,60 & 1,20 & 1,30 & 1,00 & 1,09 \\
\hline Relação NP/NA & 0,80 & 0,80 & 1,50 & 1,50 & 1,30 & 1,30 \\
\hline
\end{tabular}

TABELA 3

Susceptibilidade para seis espécies de triatomíneos às mostras de Tripanosoma cruzi isoladas do caso Humano e de Rhodnius robustus.

\begin{tabular}{|c|c|c|c|c|c|}
\hline \multirow{3}{*}{ Espécies } & \multirow{3}{*}{$\begin{array}{c}\text { Exemplares } \\
\text { alimentados } \\
\text { por cepa }\end{array}$} & \multicolumn{4}{|c|}{ Exemplares positivos por cepa } \\
\hline & & \multicolumn{2}{|c|}{ No } & \multicolumn{2}{|c|}{$\%$} \\
\hline & & $\begin{array}{l}\text { Acre } \\
\text { Humana }\end{array}$ & $\begin{array}{l}\text { Acre } \\
\text { Silvestre }\end{array}$ & $\begin{array}{l}\text { Acre } \\
\text { Humana }\end{array}$ & $\begin{array}{l}\text { Acre } \\
\text { Silvestre }\end{array}$ \\
\hline Triatome infestans & 30 & 28 & 27 & 93,33 & 90,00 \\
\hline Triatoma sordida & 30 & 30 & 30 & 100,00 & 100,00 \\
\hline Triatoma brasiliensis & 30 & 28 & 29 & 93,33 & 96,66 \\
\hline Panstrongylus megistus & 30 & 29 & 30 & 96,66 & 100,00 \\
\hline Rhadnius neglectus & 30 & 30 & 30 & 100,00 & 100,00 \\
\hline Rhodnius prolixus & 30 & 29 & 29 & 96,66 & 96,66 \\
\hline Total 6 espécies & $\begin{array}{c}180 \\
(\times 2 \text { cepas }=360)\end{array}$ & 174 & 175 & 96,66 & 97,22 \\
\hline
\end{tabular}

Cultivabilidade - As duas amostras $\mathrm{AH}$ e AS de T.cruzi, semeadas em meios artificiais líquido (Warren) ou semisólido (NNN), tiveram comportamento comum e semelhante entre si, isto é, foram facilmente cultivadas e foi obserrado sempre um bom crescimento nos repiques sucessivos realizados com intervalos regulares.
Provas de proteção - Dez camundongos da amostra $\mathrm{AH}$ e dez camundongos da amostra AS, cuja infecção evoluiu para a cronicidade, foram reinoculados com $0,2 \mathrm{ml}$ de sangue de doadores com infecção aguda pela amostra $Y$. Como testemunhos, foram inoculados $10 \mathrm{ca}$ mundongos limpos, com a mesma dose e idade 
dos utilizados nos lotes anteriores. Verificou-se que os testemunhos morreram entre o $10^{\circ}$ e $15^{\circ}$ dias após a inoculação.

Os camundongos com infecção crônica pelas duas amostras do Acre, mostraram-se resistentes, não apresentando parasitos no sangue circulante em sucessivos exames.

Foi difícil a realização da prova de proteção pois as amostras em estudo mostraram uma alta virulência; desta forma, os camundongos separados para estas provas passaram a ser inoculados com doses menores de tripomastigotas por $\mathrm{ml}$.

Correlação entre os caracteres das duas amostras em estudo - Analisando-se os resultados obtidos no estudo da infecção pode-se verificar a existência de correlação entre os caracteres de infecção das duas amostras. Assim sendo, observou-se nas duas amostras (AH e AS) infecção caracterizada por um período prepatente curto, elevadas parasitemias e alta taxa de letalidade.

$O$ estudo das duas amostras em relação às formas tissulares mostrou o mesmo quadro histopatológico.

A análise dos valores obtidos dos caracteres morfobiométricos mostrou uma pequena diferença no comprimento total médio (amostra $\mathrm{AH}-$ comprimento total médio $=25,48 \mathrm{u}$; amostra AS - comprimento total médio = 27,90 u) o que não invalida que haja uma correlação entre elas (Tabela 2).

\section{COMENTÁRIOS E CONCLUSÕES}

Diante dos dados investigados e apresentados no presente trabalho, não há dúvida quanto ao caráter autóctone do caso em discussão. Assim como, fica descartada a possibilidade de transmissão congênita ou transfusional.

As características morfobiométricas, patogênicas e biológicas das duas amostras estudadas (AH e AS) mostram que se tratam de cepas de $T$. cruzi acentuadamente patogênicas. E o estudo comparativo entre elas não apresenta varia- bilidade significativa, o que sugere uma estreita correlação e, conseqüentemente, uma forte indicação de contaminação local. Entretanto, diante da ausência de indícios de domiciliaçãa triatomínea, não fica evidente se a transmissão foi metaxênica pela invasão domiciliar de triatomíneo silvestre, provavelmente $R$. robustus, ou se foi por via digestiva através da ingestão de alimentos contaminados por fezes de barbeiros ou por excreta de reservatórios portadores de T. cruzi.

De qualquer forma, esse fato uma vez mais confirmaria a presença de biocenose silvestre na região e explicaria o desencadeamento desses casos em áreas não endêmicas e ainda com baixa alteração ambiental. Tal quadro ficou evidenciado no estudo de casos semelhantes ocorridos no ecossistema da Serra do Mar, na região Sudeste do Brasil, nos quais, guardadas as devidas ressalvas, há certo paralelismo epidemiológico. E onde foi considerado que as relações diretas do homem com vetores e reservatórios participantes dessa biocenose teriam que ser encarados como de natureza casual ou propiciados por atividades exercidas no ambiente extradomiciliar (Forattini, $1980^{11}$ e $1981^{12}$ ). Entretanto, é preciso levar em consideração que a alteração ambiental provocada pelo homem poderá deslocar esta biocenose para o ecosistema artificial à medida que este ambiente ofereça condiçōes favoráveis à domiciliação triatomínea. E isso poderia ocorrer tanto por conta da adaptação de espécies autóctones de triatomíneos primitivamente silvestres, quanto pela introdução de espécies domiciliadas de áreas endêmicas do país. E o acelerado processo de colonização, pelo qual está sendo submetida a Amazônia, provocando intensa imigração, muitas vezes proveniente de áreas endêmicas do Brasil e desencadeando uma profunda alteração ambiental na região, poderia acelerar essa domiciliação. Advindo daí a necessidade de manutenção, pelos Serviços de Saúde competentes, de uma vigilância entomológica adequada, que facilite a percepção dos indícios de domiciliação e assim, talvez, se possa evitar que se instale na região um processo de domiciliação de difícil e complexo controle. 
BARATA, J.M.S. et al. (The first autochthonous case of American trypanosomiasis in the State of Acre, Brazil, and its correlation with the strains identified in the human case and the sylvatic triatomines in the area]. Rev. Saude públ., S. Paulo, 22:401-10, 1988.

\begin{abstract}
Results of entomological and epidemiological investigations on the first autochthonous human case of American trypanosomiasis in the State of Acre, Brazil are presented. There are no synanthropic triatomine vectors in the area. Possibility of congenital or transfusional transmission is completely excluded. However, it is not possible to establish whether transmission was the result of house invasion of a silvatic triatomine species or contamined food. Two strains of Trypanosoma cruzi were isolated: one from humans which was called "Acre-Humana" (AH) and another from Rhodnius robustus collected in palm-trees (Attalea sp.) near the dwelling, called "Acre-Silvestre" (AS). There is a close relationship between the strains of $T$. cruzi studied, in both morphological and pathogenic aspects. These strains are pathogenic for baby mice, showing an infection rate of one hundred per cent. In both strains, the mice infection was very severe, with high lethality and parasitemia rates and a short prepatente period. In both strains during the acute infection phase, leishmanial forms were easily seen in tissue sections, specially in mice hearts and livers. Mice which recovered from infection with the AH and AS strain had a high resistence against reinoculations with the Y strain of $T$. cruzi. AH and AS strains were easily cultivated in blood-agar medium and Warren's liquid medium and infected six species of triatomine tested. The results confirm once again the existence of natural focci of American trypanosomiasis in the area.
\end{abstract}

UNITERMS: Trypanosomiasis, South American. Trypanosoma cruzi, isolation. Rhodnius robustus, parasitology. Triatomidae, parasitology. Disease reservoirs.

\title{
REFERENCIAS BIBLIOGRÁFICAS
}

1. ALBUQUERQUE, R.D.R. \& BARRETO, M.P. Estudos sobre reservatórios e vectores silvestres do Trypanosoma cruzi. XXVI - Infecção natural do rato d'água, Nectomys squamipes squamipes (Brants, 1827) pelo T. cruzi. Rev. Inst. Med. trop. S. Paulo, 10:229-37, 1968 .

2. AlBUQUERQUE, R.D.R. \& BARRETO, M.P. Estudos sobre reservatórios e vectores silvestres do Try. panosoma cruzi. XXX - Infeç̧ão natural do Cachorro do Mato, Cerdocyon thous azarae (Wied, 1824) pelo T. cruzi. Rev. bras. Biol., 28:457-68, 1968.

3. ALMEIDA, F.B. Triatomíneos da Amazônia. Encontro de três espécies infectadas por Trypanosoma semelhante ao cruzi, no Estado do Amazonas. (Hemiptera - Reduviidae), Acia amazon., 1:89-93, 1971.

4. ALMEIDA, F.B. \& NUNES DE MELLO, J.A. Sobre a ocorrência da molestia de Chagas no Estado do Amazonas, Brasil. Acta amazon., 8:595-9, 1978.

5. CASTRO FERREIRA, L. de \& DEANE, L. Novo depositário silvestre do Schizotrypanum cruzi (Chagas, 1900): a irára, Tayra barbara. Bras. med., 52:1159-61, 1938.

6. DEANE, L.M. Tripanossomídeos de mamiferos da região amazônica. III - Hemoscopia e xenodiagnóstico de animais silvestres dos arredores de Belém, $\mathrm{Pa}$ rá. Rev. Inst. Med. trop. S. Paulo, 6:225-32, 1964.

7. DEANE, M.P. \& DAMASCENO, R.M.G. Encontro do Panstrongylus lignarius naturalmente infectado por Tripanosoma do tipo "cruzi" e algumas no. tas sobre sua biologia. Rev. Serv. esp. Saúde puibl., 2:809-14, 1949.

8. DEANE, L. \& JANSEN, G. Encontro de Schizotrypanum cruzi (Chagas, 1909) em marsupiais da espécie Marmosa cinerea Desmarest. Bras. med., 53:265-6, 1939.

9. DOREA, R.C.. Doença de Chagas na Amazônia: aspectos epidemiológicos regionais e considerações a propósito de um caso pediátrico. Hiléia med., Belém, 3:81-109, 1981.

10. FORATTINI, O.P.; ROCHA E SILVA, E.O.; BA-
RATA, J.M.S.; BOAINAIN, E. Nota sobre caso autóctone de tripanossomíase americana no litoral sul do Estado de São Paulo, Brasil. Rev. Saúde públ., S. Paulo, 14:143-9, 1980.

11. FORATTINI, O.P.; ROCHA E SILVA, E.O.; BARATA, J.M.S.; BOAINAIN, E. Nota sobre novo caso autóctone de tripanossomíase americana no litoral sul do Estado de São Paulo, Brasil. Rev. Saúde públ., S. Paulo, 15:350-2, 1981.

12. FRANÇA, M.S.; FRADE, J.M.; KONASUGAWA, K.; ALMEIDA, F.B. Doença de Chagas: primeiro caso autóctone na Amazônia Ocidental, Amazonas, Brasil. Acta amazôn., 10:759-62, 1980.

13. LACERDA JR., K.G.; FARIA, J.I.M.; MATTE, J.R.; COSTA, R.; SALGADO, A.; MOURÃO, O.; SANTOS, C.A.B.; NOHMI, N. Doença de Chagas: registro do primeiro diagnóstico feito no homem, no Território Federal do Amapá. In: Congresso Sociedade Brasileira de Medicina Tropical, 10․, Curitiba, 1974. Programa e sumários. Curitiba, Sociedade Brasileira de Medicina Tropical/Secretaria da Saúde do Estado do Paraná, 1974. Res. n: 32.

14. LAINSON, R.; SHAW, J.J.; FRAIHA, H.; MILES, M.A.; DRAPER, C.C. Chagas' disease in the Amazon Basin. 1 - Trypanosoma cruzi infections in silvatic mammals, triatomine bugs and man in the State of Pará, north Brazil. Trans. roy. Soc. trop. Med. Hyg., 73:193-204, 1979.

15. MILES, M.A. The epidemiology of South American Trypanosomiasis: biochemical and immunological approaches and their relevance to control. Trans. roy. Soc. trop. Med. Hyg., 77:5-23, 1983.

16. RODRIGUES, B.A. \& BRITO MELO, G. de Contribuição ao estudo da tripanossomiase americana. Mem. Inst. Oswaldo Cruz, Rio de Janeiro, 37:77-90, 1942.

17. RODRIGUES, I.R.C.; SOUZA, A.A. de; VALENTE, S.A.S. Novo caso autóctone de doença de Chagas no Estado do Pará. In: Congresso da Sociedade Brasileira de Parasitologia, 9., Fortaleza, 1985. Programação e resumo de temas livres. Fortaleza, Sociedade Brasileira de Parasitologia, 1985. p. 22. 
18. RODRIGUES, I.R.C.; SOUZA, A.A. de; TERCEROS, R.O.; VALENTE, S.A.S. Doença de Chagas na Amazônia: registro da ocorrência de 8 casos autóctones em Macapá [Resumo]. Rev. Soc. bras. Med. Trop., Brasília, 19(supl):43, 1986. [Apresentado ao 22: Congresso da Sociedade Brasileira de Medicina Tropical, Belo Horizonte, 1986].

19. SHAW, J.; LAINSON, R.; FRAIHA, H. Consideraçōes sobre a epidemiologia dos primeiros casos autóctones de doença de Chagas registrados em Belém, Pará, Brasil. Rev. Saúde públ., S. Paulo, 3(2):153-7, 1969.

20. SILVEIRA, F.T.; DIAS, M.G.V.; PARDAL, P.P.; LOBÃO, A.O.; MELO, G.B. Nono caso autóctone de doença de Chagas registrado no Estado do Pará, Brasil. Hiléia med., Belém, 1:61-2, 1979.

21. SOUZA LIMA, M.Z.M.; MIRANDA SANTOS, I.K.F. de; SOUZA, A.A.A. de; NAIFF, R.D.; CZECO, Y.M.T.; MILES, M.A. Caso humano de infecção mista por Trypanosoma cruzi e organismo tipo Trypanosoma rangeli procedente de Barcelos, Rio Negro, Amazonas. In: Congresso da Sociedade Brasileira de Medicina Tropical, 21. , São Paulo, 1985. Programa e resumos. São Paulo, Sociedade Brasileira de Medicina Tropical, 1985, p. 44.

Recebido para publicaçâo em 12/4/1988 Aprovado para publicação em 20/6/1988 